\title{
Effect of educational intervention on practice improvement of employees in healthcare centers and meat distribution centers of Ilam province about Crimean Congo hemorrhagic fever
}

Fariba Mokhtari ${ }^{1}$, Narges Sharifinia ${ }^{1}$, Zahra Mokhtari $^{2}$, Mostafa Qorbani ${ }^{3}$, Hadad Shafieyan $^{4}$, Babak Rastgari Mehr ${ }^{5}$, Amin Mirzai ${ }^{1}$, Zahra Shafieyan ${ }^{6}$, Morteza Mansourian*1

1. Department of Public Health, Faculty of Health, Ilam University of Medical Sciences, Ilam, Iran

2. Department of Clinical Pathobiology, Azad University, Sanandaj, Iran

3. Departments of Community Medicine, School of Medicine, Alborz University of Medical Sciences, Karaj, Iran

4. Department of Pathobiology, Faculty of Veterinarian, Shahid Chamran University, Ahvaz, Iran

5. Department of Public Health, Faculty of Health, Abadan School of Medical Sciences, Abadan, Iran

6. Student Research Committee, Ilam University of Medical Sciences, Ilam, Iran

*Corresponding author: Tel: +98 9126585129 Fax: +98 8432227134

Address: Department of Public Health, Faculty of Health, Ilam University of Medical Sciences, Ilam, Iran E-mail: mansourian55@gmail.com

Received; 2015/06/27 revised; 2015/07/30 accepted; 2015/09/6

\section{Abstract}

Introduction: Crimean Congo hemorrhagic fever (CCHF) is a Zoonosis disease. The aim of this study was to examine the effect of educational intervention on practice improvement of employees in healthcare centers and meat distribution centers of Ilam province in relation to Crimean Congo hemorrhagic fever.

Materials and methods: Participants in present quasi-experimental study were 200 employees of healthcare centers and 75 workers of meat distribution centers that were selected through simple random sampling. Data were collected at baseline and 6-weeks after intervention using two 38-item and 50-item questionnaires. Data were analyzed by the SPSS software. $\mathrm{P}<0.05$ were considered to be statistically significant.

Results: Before the educational intervention, $20.6 \%$ of the healthcare centers employees had poor knowledge, $61.8 \%$ and $17.6 \%$ had average and good knowledge, respectively. After educational intervention, these percentages were $2 \%, 22.1 \%$ and $76 \%$; in that order. The workers' knowledge level in centers of meat processing-distribution before training was $64 \%$ poor, $34.7 \%$ average, and $1.3 \%$ good; but after education, the knowledge levels reached to $5.3 \%, 45.3 \%$ and 49.3\%; respectively $(\mathrm{P}<0.05)$. Moreover, Attitude of employees in healthcare centers and meat distribution centers significantly increased after intervention $(\mathrm{P}<0.05)$. But, there were not significant changes in performance of two groups before and after educational intervention

Conclusion: The results of present study showed the effect of educational intervention on improvement the knowledge, attitude of employees in healthcare and meat distribution centers. So, implementation of an educational program for employees at a wider scale could promote their health.

Keywords: CCHF, Behavior, Health care employees, Intervention

\section{Introduction}

Crimean-Congo hemorrhagic fever $(\mathrm{CCHF})$ is a severe viral infection 
$30 \%$. $\mathrm{CCHF}$ is endemic in large areas of Africa as well as East and Central Europe. Significant cases of CCHF have increased in countries such as Kosovo, Albania, Turkey and Iran. Recently, this disease has been observed and reported in Greece (1). In terms of gender distribution, the male three times more infected with this disease in comparison with the females; as well, regarding the age distribution of the disease, $\mathrm{CCHF}$ is more common at the age range of 21-40 years old (2).

The cause for CCHF viral disease is of the category of single-stranded RNA from the Bionaviridae family and the genera Nairovirus $(3,4)$. The main carrier and source of this virus in nature is from the Ixodidae family (hard ticks), the genera Hialomavires, and Marginatum species. This disease has the broadest geographical distribution among known viruses transmitted by ticks that are medically important (5). Transmission of this virus is caused through contacts with blood and other secretions or even the contaminated tissues of infected patients with bleeding in the hospital or at home. As well, the disease could be transmitted through surgical implements, needles or sharp instruments infected with CCHF patients' blood at hospital. Similar to other diseasecausing factors for hemorrhagic fevers, $\mathrm{CCHF}$ factor is grouped in the fourcategory biodiversity of four-level biological classification and its cause is also human-to-human transmission, high risk for nosocomial and laboratory infections, as well as lack of vaccines for this disease. This factor is also one of the classified factors to be used in bioterrorism and there are specific rules to work with this disease factor in different countries (8).

The viral hemorrhagic fevers are a group of diseases that have symptoms of bleeding due to causing disorders in blood coagulation system. That is why this disease is characterized by bleeding from different parts of the body. In the first stage of these diseases following short incubation period (usually less than a week); the common symptoms include fever, weakness, muscle pain, headache, sore throat, loss of appetite, dizziness, nausea, vomiting, diarrhea or abdominal pain. Some of these diseases are associated with mental and neuralsymptoms such as drowsiness, depression, and dysphoria. The secondary symptoms related to bleeding in the gastrointestinal tract include vomiting blood or traces of blood in the excrement (tarry feces). The mucosal bleeding is in the form of bleeding gums, mouth, throat or nose. The urinary tract or genital bleeding is as hematuria (blood pissing) or female genital bleeding. Most of the diseases in this group are associated with high mortality rates in which the main cause of the disease is the internal flows of bleeding (9).

With the prevalence of CCHF in the years 1998-1999 in Afghanistan, Pakistan, Iraq and ensuing the illegal transfer of infected animals from the mentioned countries to Iran; this disease also spread in Iran in 1999. The prevalence of this disease in Iran was also confirmed by sending patients' serum samples to WHO reference laboratory. Following the death of a physician inflicted with the disease in the city of Shahrekord, the ministry of health authorities realized the need to prevent, control of CCHF (10).

In Iran, the most important way of getting inflicted is slaughtering infected animals, or having contacts with carcasses or their blood and guts after they have been slaughtered. Therefore, education to society about the slaughter of the livestock in slaughter houses and the use of protective equipment are of utmost importance (10). The mortality rate by CCHF has been reported about 5-50 percent $(5,11)$. This Zoonosis disease is wide spread in many of the neighboring countries of Iran and across the world (12). Twenty-three provinces of Iran have been infected with CCHF (1). 
Due to the importance of CCHF; people, healthcare and meat distribution workers in local areas should become aware of the presence of the disease, its modes of transmission, the risk of nosocomial infections and the control as well as the protective measures against the disease. Here, Ilam Province in western Iran has long common borders with Iraq, and a great number of passengers are exchanged at the borders between the two countries; therefore, the aim of this intervention study was effect of educational intervention on practice improvement of employees in healthcare centers and meat distribution centers of Ilam province about CCHF in 2014.

\section{Materials and method}

This research was a quasi-experimental study. The data were collected by using two researcher-made questionnaires. Due to the differences in educational levels of study groups, two sets of questionnaires were provided and distributed among employee in healthcare centers and meat distribution centers worker. After designing the questionnaires, they were submitted to five experts in the field of infectious diseases, entomology and health education to confirm their validity. After that, the required modifications were made. In order to evaluate the reliability of the questionnaire, test re test method was used and the Cronbach's alpha For the questionnaires given to the workers in healthcare and meat distribution centers were 0.78 and 0.75 ; respectively. The questionnaires were contained:

1) The questionnaire for the employees in healthcare centers included 4 demographic questions, 22 knowledge, 8 attitude and 11 practice questions .

2) The questionnaire for the workers in meat distribution centers were composed of 4 demographic questions, 18 knowledge, 11 attitude and 17 practice questions .
The scoring procedure for knowledge and performance questions were 2,1 , and 0 for true, do not know and false answer; respectively. The scoring was in the form of five-scale Likert-type for the attitude questions including 5 for totally agree, 4 for agree, 3 for neutral, 2 disagree and 1 totally disagree. To determine the sample size, given that the entire employees of the Center of the occupational and environmental health and Fight against diseases in Ilam Province were 491 people and the meat distribution centers were 151; the sample size for the employees of healthcare centers in Ilam province were 200 and for the butcheries were 75 people. The data were obtained through simple random sampling. This study was conducted in two phases. Firstly, the pretest was administered and the questionnaires were given to the two groups of the study. Then, the educational pamphlets and CDs about CCHF disease were given to the participants. Six weeks later, the participants felled the same questionnaires and their levels of change in knowledge, attitude and practice were measured. After collecting the questionnaires, to analyze the data the scores before and after of intervention for the levels of knowledge, attitude and practice were classified in good, moderate and poor level. The data were analyzed by using SPSS software and paired t-test, $t$ test and One-Way ANOVA at the significant level less than 0.05 .

\section{Results}

The ages of $46.1 \%$ of the participants were $31-40$ years old and $5 \%$ of participants were $60-51$ years old. $46 \%$ of participants had master's degree and $3.9 \%$ had doctoral education degrees. $54.9 \%$ of the participants also had 1-10 years of working experience and $12.3 \%$ of individuals with a history of working experience were 2130 years old. The percentage of the married and single participants was $79.4 \%$ and $20.6 \%$; respectively. 
The results of the data analysis revealed that there is no significant difference between knowledge, attitude and practice of the employees about CCHF disease before education. The knowledge level of $20.6 \%$ of the employees was poor, $61.8 \%$ average, and $17.6 \%$ good. After educational intervention, these levels reached to $2 \%, 22.1 \%$ and $76 \%$; respectively. This difference was statistically significant ( $\mathrm{p}$-value $<0.05$ ). Considering the workers in meat distribution, the level of knowledge before of education intervention was $64 \%$ poor, $34.7 \%$ average, $1.3 \%$ good. After education, these percentages changed in order into $5.3 \%, 45.3 \%$ and $49.3 \%$. The difference was statistically significant. These results are shown in Table 1 .

The attitude of the health centers employees about CCHF before intervention was $24.5 \%$ poor, $27.9 \%$ average and $47.5 \%$ good. After education, they respectively turned into $3.9 \%, 21.1 \%$ and $75 \%$. This difference was statistically significant ( $p$-value $<0.05$ ). The level of attitude among the workers of meat distribution before education was $36 \%$ poor, $18.7 \%$ average, and $45.3 \%$ good which changed in that order into $2.7 \%$, $5203 \%$, and $45.3 \%$. This difference was statistically significant (p-value $<0.05$ ) and the results are illustrated in Table 2 .

The practice level was determined by means of questionnaires and observations by the researchers on the changes in the health conditions of the meat distribution shop. $28.9 \%$ practice of the workers was weak, $50.5 \%$ was average and $20.6 \%$ was good. These score changed into $13.7 \%$, $61.3 \%$ and $25 \%$ after education respectively but this difference was not statistically significant. In addition, the workers in the meat distribution had $25.3 \%$ weak, $30.7 \%$ average, and $44 \%$ good practice which changed into $13.3 \%, 40 \%$, and $47.6 \%$ respectively. This difference was statistically significant and the results are represented in Table 3 .

$\mathrm{T}$ and one-way ANOVA test was used which showed no significant relationship between the demographics variable like age, job experience, education level and marital status of the employees in healthcare centers and meat distribution worker, and the level of knowledge, attitude and practice about CCHF disease.

Table1. Comparing the level of knowledge of the employees in healthcare centers with the workers of meat distribution centers in Ilam Province before and after of educational intervention.

\begin{tabular}{lcccc}
\hline & \multicolumn{2}{c}{ Employees in healthcare centers } & \multicolumn{2}{c}{ Workers in butcheries } \\
\hline Knowledge & Before intervention & After intervention & Before intervention & After intervention \\
\hline Weak & $42(20.6)$ & $4(2)$ & $48(64)$ & $4(5.3)$ \\
Average & $126(8.16)$ & $45(22.1)$ & $26(34.7)$ & $34(45.3)$ \\
Good & $36(17.6)$ & $155(76)$ & $1(1.3)$ & $37(49.3)$ \\
\hline
\end{tabular}

Table 2. Comparing the attitude of the employees in healthcare centers with the workers of meat distribution centers in Ilam Province before and after education.

\begin{tabular}{lcccc}
\hline & \multicolumn{2}{c}{ Employees in healthcare centers } & \multicolumn{2}{c}{ Workers in butcheries } \\
\hline Attitude & Before intervention & After intervention & Before intervention & After intervention \\
\hline Weak & $50(24.5)$ & $8(3.9)$ & $27(36)$ & $2(2.7)$ \\
Average & $57(27.9)$ & $43(21.1)$ & $14(18.7)$ & $39(52.3)$ \\
Good & $97(47.5)$ & $155(75)$ & $34(45.3)$ & $34(45.3)$ \\
\hline
\end{tabular}

Table 3. Comparing the performance of the employees in healthcare centers with the workers of meat distribution centers in Ilam Province before and after education.

\begin{tabular}{lcccc}
\hline & \multicolumn{2}{c}{ Employees in healthcare centers } & \multicolumn{2}{c}{ Workers in butcheries } \\
\hline Performance & Before intervention & After intervention & Before intervention & After intervention \\
\hline Weak & $59(28.9)$ & $28(13.7)$ & $19(25.3)$ & $10(13.3)$ \\
Average & $103(50.5)$ & $125(61.3)$ & $23(30.7)$ & $30(40)$ \\
Good & $42(20.6)$ & $51(25)$ & $33(44)$ & $35(47.6)$ \\
\hline
\end{tabular}




\section{Discussion}

In the present study, more than half of the workers in meat distribution centers and employees of healthcare centers had low knowledge about CCHF disease which reveals that these individuals need to know about this disease. In a study by Sargianou et al (13), high knowledge about CCHF disease has been considered as a fundamental solution to deal with this disease. Moreover, in a study by Gungormus and colleagues (14); 71\% of the participants were informed about CCHF disease, which was higher than the level of knowledge among the participants of the present study. As well, in a research by Ozer et al (15); $50.4 \%$ of the participants had good knowledge about the disease and its modes of transmission. In Arikan et al.'s study (16) in Turkey, the knowledge level of participants about $\mathrm{CCHF}$ disease was higher than the findings of the present study, and this level of knowledge in women with high-school education or higher and male farmers was more than others.

However, in a study conducted by Sheikh et al (17) among the experts in healthcare centers, the low level of knowledge among the participants was in line with the present study. Since the samples under study were individuals subjected to this disease, there is a need to implement educational programs for these groups.

In terms of the individuals' attitude, one third of the participants in both study groups had negative attitude to the means of prevention for CCHF disease. In study by Vancelik et al (18) in Turkey, the participants obtained low scores in their attitude questionnaires and female participants' scores were lower than male participants' scores.

The results of the current study showed that individuals' education has an impact on their knowledge about CCHF disease; although this relationship was not statistically significant. These findings were consistent with the studies by Yilmaz et al. (19), Cilingirolu et al. (20) and Taghdici et al. (21). In our study; before education, a small percentage (10\% of the workers in meat processing-distribution centers and $25 \%$ of the employees in healthcare centers) of the participants considered ticks as the transmission cause of CCHF disease which was not in agreement with the results of a study by Cilingiroglu et al. (20) in Ankara, where $89.8 \%$ of the study population considered ticks as the cause of transmission for CCHF disease. As well, Kartal and colleagues' study (22) in an area with CCHF endemic in Turkey showed that $58 \%$ of people are familiar with CCHF disease, while the number of people who were aware of the ways of transmission of the disease was low. As ticks are the main cause of transmission for this disease, and the participants in the present study are individuals who are directly or indirectly in contact with stocks; they are required to have enough knowledge about the disease and its modes of transmission and control. Therefore, the health authorities in Ilam Province are obliged to have the necessary planning in order to control and prevent of $\mathrm{CCHF}$ disease.

The results of the present study demonstrated that there is a significant difference between knowledge, attitude, and performance of the workers in meat distribution centers in Ilam Province about CCHF disease before and after education. The findings are consistent with the results of the study by Izadi et al in 2004 in which it was revealed that age, gender, living environment (urban vs. rural), degree of education, occupation, history of tick bites, history of contact with animals, history of stock slaughter, the presence of a designated area for animals at home, history of living with or keeping animals at home increase the risks for being infected with CCHF disease. These results were in contrast with the results of the study by Williams et al (23) in which serology on 
animals subjected to the disease and workers in meat distribution centers was studied. In the present study, the practice scores of participants before and after the implementation of educational intervention were not statistically significant, but the scores obtained by healthcare centers workers and workers in meat distribution had increased. In a study by Sheikh and colleagues (18), the participants' level of practice regarding $\mathrm{CCHF}$ disease was weak which was consistent with the results of the present study. According to the results and effect of educational intervention on improvement knowledge,

\section{References}

1. Chinikar S, Ghiasi SM, Moradi M, Goya MM, Shirzadi MR, Zeinali M, et al. Geographical distribution and surveillance of Crimean-Congo hemorrhagic fever in Iran. Vector Borne Zoonotic Dis. 2010; 10(7): 7058.

2. Chinikar S, Persson S M, Johansson M, Bladh L, Goya M, Houshmand B, et al. Genetic analysis of crimean-congo hemorrhagic fever virus in Iran. J Med Virol. 2004; 73: 404-11.

3. World Health Organization (WHO). Crimean Congo hemorrhagic fever. Fact Sheet. No 208. 2001; 25-6.

4. Chin J. Control of communicable diseases manual. 18th edition. Washington DC: American Public Health Association; 2004; 24-7.

5. Zavitsanou A, Babatsikou F, Koutis C. Crimean Congo hemorrhagic fever: an emerging tick- borne disease. Health Sci J. 2009; 3(1): 10-8.

6. Chinikar S, Goya MM, Shirzadi MR, Ghiasi SM, Mirahmadi R, Haeri A, et al. Surveillance and laboratory detection system of Crimean-Congo haemorrhagic fever in Iran. Transbound Emerg Dis. 2008; 55(1): 200-4.

7. Emadi K, Reza Y, Haji Abdul Baqi M, Soodbakh H. Crimean-Congo attitude of employees in healthcare and meat distribution centers of Ilam province; it is suggested to implement educational programs about CCHF disease for at-risk groups such as employee in healthcare centers as well as workers in meat distribution centers and ranchers.

\section{Acknowledgements}

This paper is the final result of the research proposal which has been approved by the ethical committee of Ilam University of medical sciences. The authors express their thanks to all the participants of this study.

hemorrhagic fever in the world and in Iran. J Tehran Uni Med Sci. 2003;5 (2): 343-58.

8. Majidzadeh $\mathrm{K}$, Soleimaini $\mathrm{M}$, Ghelianchi Langroodi A. A review of the Crimean-Congo hemorrhagic fever laboratory diagnosis methods. Scientific-Research J Army Uni Med Sci. 2011; 9(4): 275-84.

9. Parola P, Raoult D. Ticks and tickborne bacterial diseases in humans: an emerging infectious threat. Clin Infec Dis. 2001; 32(3): 897- 906.

10. Mostafavi E, Haghdoost A, Khakifirouz S, Chinikar S. Spatial analysis of Crimean Congo hemorrhagic fever in Iran. Am J Trop Med Hyg. 2013; 89(6):1135-41.

11. Knust B, Medetov ZB, Kyraubayev $\mathrm{KB}$, Bumburidi $\mathrm{Y}$, Erickson BR, MacNeil A, et al. Crimean-Congo hemorrhagic fever, Kazakhstan, 20092010. Emerg Infect Dis. 2012; 18(4): 643-5.

12. Butterfield PG. Upstream reflections on environmental health: an abbreviated history and framework Sargianou M1, Papa A. Epidemiological and behavioral factors associated with Crimean-Congo hemorrhagic fever virus infections in humans. Expert Review Anti Infect Treat. 2013; 11(9): 897-908. 
13. Gungormus Z, Kiyak E. Evaluation of knowledge about protection against Crimean-Congo hemorrhagic fever. Southeast Asian J Trop Med Public Health. 2011; 42(3):737-43.

14. Ozer A, Miraloglu M, Cetin Ekerbicer H, Cevik F, Aloglu N. Knowledge levels about Crimean-Congo hemorrhagic fever among midwifery and nursing students in Kahramanmaras, Turkey. Southeast Asian J Trop Med Public Health. 2010; 41(1): 77-84.

15. Arikan I1, Kasifoglu N, Metintas S, Kalyoncu C. Knowledge, beliefs, and practices regarding tick bites in the Turkish population in a rural area of the Middle Anatolian Region. Trop Anim Health Prod. 2010;42(4):669-75.

16. Sheikh NS, Sheikh AS, Sheikh AA. Knowledge, attitude and practices regarding Crimean-Congo haemorrhagic fever among healthcare workers in Balochistan. J Ayub Medical College Abbottabad. 2004; 16(3): 39-42.

17. Vançelik S, Avşar U, Aktürk Z. [Knowledge, attitudes, and behavior of people living in rural areas of Erzurum about Crimean-Congo hemorrhagic fever]. Turkiye Parazitol Derg. 2012; 36(3):156-9. [Turkish]

18. Yilmaz R, Ozcetin M, Erkorkmaz U, Ozer S, Ekici F. Public knowledge and attitude toward Crimean Congo hemorrhagic fever in Tokat Turkey.
Iran J Arthropod-Borne Disease. 2009; 3(2): 12-17.

19. Cilingiroglu N, Temel F, Altintas $\mathrm{H}$. Public's Knowledge, Opinions and Behaviors about Crimean-Congo Hemorrhagic Fever: An Example from Turkey. Kafkas University Veterinarian Fakulty Dergisi. 2010; 16 (Suppl-A): 17-22.

20. Taghdisi M, Sasooli H, Ramezani A. A study of level the nurse's knowledge of the CCHF disease in the Sistan. Zahedan Journal of Research Medical Sciences. 2012; 13(1): 65.

21. Kartal M, Aydin B, Tulek N, Acicbe O, Tanyel E, Fisgin N. The Knowledge and Attitudes of people at High Risk for crimean-congo Hemorrhagic fever: A cross-sectional survey from an Endemic Region in Turkey. Turkish Iran J Arthropod Borne Dis. 2009; $3(2): 12-7$.

22. Izadi S, Naieni KH, Madjdzadeh SR, Nadim A. Crimean-Congo hemorrhagic fever in Sistan and Baluchestan Province of Iran, a casecontrol study on epidemiological characteristics. Int J Infect Dis. 2004; 8(5):299-306.

23. Williams RJ, Al-Busaidy S, Mehta FR, Maupin GO, Wagoner KD, Al-Awaidy $\mathrm{S}$, et al. Crimean-congo haemorrhagic fever: a seroepidemiological and tick survey in the Sultanate of Oman. Trop Med Int Health. 2000;5(2):99-106. 